\title{
Analisis Pemanfaatan Geothermal Brine untuk Pembangkitan Listrik dengan Heat Exchanger
}

\author{
Aloysius Afriandi, Ridho Hantoro \\ Jurusan Teknik Fisika, Fakultas Teknologi Industri, Institut Teknologi Sepuluh Nopember (ITS) \\ e-mail: aloysius13@mhs.ep.its.ac.id, ridho_hantoro@yahoo.com
}

\begin{abstract}
Abstrak-Geothermal atau Panas Bumi merupakan salah satu sumber energi yang tergolong ke dalam jenis energi baru dan terbarukan. Dalam pemanfaatannya, proses pembangkitan listrik panas bumi pada PLTP dengan sumber panas bumi dengan entalpi tinggi seringkali membuang cairan panas bumi atau brine. Brine ini sendiri memiliki potensi termal dari 148 $173^{\circ} \mathrm{C}$ sehingga masih berpotensi untuk dijadikan energi dalam pembangkitan dengan menggunakan siklus biner. Siklus biner sendiri merupakan siklus pembangkitan listrik yang dalam prosesnya menggunakan bantuan fluida sekunder atau fluida kerja bertitik didih rendah untuk mengoptimalkan vapor yang dihasilkan oleh fluida sekunder tersebut dengan panas yang tersedia. Fluida kerja yang digunakan dalam penelitian ini antara lain R134a, n-pentana, dan isobutana. Dari ketiga jenis fluida kerja tersebut didapatkan bahwa n-pentana merupakan fluida kerja yang paling baik jika ditinjau dari daya yang dihasilkan yaitu sebesar $14980 \mathrm{~kW}$ dan ditinjau dari efisiensi eksergetiknya yaitu $68,7 \%$.
\end{abstract}

Kata kunci-Panas Bumi, Brine, Siklus Biner, Efisiensi Eksergetik

\section{PENDAHULUAN}

$\mathrm{P}$ ANAS bumi atau geothermal merupakan salah satu sumber energi baru terbarukan yang terbentuk di dalam kerak bumi. Di Indonesia sendiri, sumber energi geothermal tergolong cukup potensial. Kategori geothermal yang terdapat di Indonesia sendiri tergolong ke dalam kategori entalpi menengah hingga entalpitinggi. Dengan demikian, geothermal dapat dijadikan salah satu alternatif pembangkitan listrik untuk mendukung peningkatan rasio elektrifikasi di Indonesia[1].

Dalam proses pembangkitan listrik PLTP, panas bumi langsung dieksploitasi dan dimanfaatkan tekanannya untuk memutar turbin setelah melalui separator dan demister. Panas bumi sendiri dikatakan sumber energi baru dan terbarukan karena fluida sisa dari panas bumi baik itu hasil separasi pada separator atau fluida sisa hasil kerja dalam siklus pembangkitan diinjeksikan kembali ke dalam reservoir agar reservoir dapat kembali menampung panas bumi untuk kembali dieksploitasi.

Brine sendiri seperti yang telah dijelaskan sebelumnya merupakan produk hasil separasi uap pada separator. Pada kategori panas bumi berentalpi tinggi, temperatur dari brine sendiri bisa mencapai $150^{\circ} \mathrm{C}$. Dengan temperatur tersebut, brine masih berpotensi untuk dijadikan sumber energi pembangkitan dalam skala kecil.
Untuk kategori geothermal pada lokasi Jawa Barat sendiri dan yang akan dijadikan objek penelitian, temperatur brine dari sumur hingga $173^{\circ} \mathrm{C}$ dengan mass flow rate $252 \mathrm{~kg} / \mathrm{s}$ dan entalpi sekitar $732,4 \mathrm{~kJ} / \mathrm{kg}[2]$.

Pada beberapa negara yang memanfaatkan panas bumi sebagai energi pembangkit, brine hanyalah dianggap sebagai prodak buangan dan tidak termasuk ke dalam siklus pembangkitan secara langsung. Bagi industri, menginjeksikan brine langsung ke reservoir tentunya lebih mudah dan tidak beresiko. Namun, dengan begitu potensi termal dari brine sendiri menjadi sia-sia. Padahal jika saja brine dimanfaatkan untuk pembangkitan dalam skala kecil, mungkin saja dapat digunakan untuk masyarakat sekitar. Industri pembangkitan pun tidak akan dirugikan mengingat ketika temperatur dari brine telah berhasil diekstraksi, fluida sisanya akan tetap diinjeksikan ke reservoir sehingga manajemen dan treatment dari reservoir akan tetap terjaga[2].

Proses yang dapat dilakukan untuk pembangkitan sendiri adalah dengan mengekstraksi termal dari brine dengan heat exchanger (HE). Dengan mengekstraksikan termal dari brine, termal tersebut kemudian akan memanaskan fluida kerja yang kemudian akan dialirkan ke turbin. Setelah digunakan untuk proses pembangkitan, fluida sisa kemudian akan kembali diinjeksikan ke reservoir sebagai upaya manajemen reservoir panas bumi[3].

\section{URAIAN PENELITIAN}

\section{A. Analisis Eksergi}

Analisis eksergi pada penelitian ini bertujuan untuk mengetahui ketersediaan energi dalam siklus biner geothermal brine. Analisis sendiri dilakukan dengan memahami setiap komponen dan kemungkinan terjadinya pemusnahan energi pada setiap komponen siklus biner geothermal brine.

Fase-fase yang dianalis is pada siklus ini, antara lain:

- Heat Exchanger

- Temperatur brine masuk heat exchanger

- Temperatur brine keluar heat exchanger

- Laju aliran brine masuk heat exchanger

- Laju aliran brine keluar heat exchanger

- Temperatur udara masuk heat exchanger

- Temperatur udara keluar heat exchanger

- Tekanan udara masuk heat exchanger

- Tekanan brine masuk heat exchanger 
- Tekanan brine keluar heat exchanger

- Turbin

- Temperatur vapor masuk turbin

- Tekanan vapor masuk turbin

- Temperatur vapor keluar turbin

- Tekanan vapor keluar turbin

- Kondensor

- Temperatur vapor masuk kondensor

- Tekanan vapor masuk kondensor

- Laju aliran cooling water

- Temperatur cooling water keluar kondensor

- Tekanan cooling water keluar kondensor

- Laju aliran cooling water keluar kondensor

- Temperatur cooling water inlet

- Temperatur cooling water outlet

- Tekanan cooling water inlet

- Tekanan cooling water outlet

Perhitungan analisis eksergi pada penelitian ini sendiri dilakukan dengan menggunakan persamaan:

$$
\mathrm{x}_{\text {state }}=\mathrm{h}_{\text {state }}-\mathrm{h}_{\text {ling kungan }}-\left(\mathrm{T}_{\text {lingkungan }} \times\left(\mathrm{s}_{\text {state }}-s_{\text {lingkungan }}\right)\right.
$$

Persamaan di atas digunakan untuk memperoleh eksergi spesifik pada state-state yang telah ditentukan sebelumnya.

Setelah diperoleh eksergi spesifik, dilakukan perhitungan terhadap laju eksergi dengan persamaan:

$$
\mathrm{E}_{\text {state }}=\dot{\mathrm{m}}_{\text {state }} \times \mathrm{x}_{\text {state }}
$$

dimana E merupakan laju eksergi dan ṁ merupakan laju aliran. Analisis pemanfaatan sistem pembangkit geothermal sendiri banyak dilakukan dengan menggunakan analisis eksergetik[4]. Sebelum dapat dianalisis efisiensi eksergetik pada sistem, terlebih dahulu harus diketahui rugi eksergi yang terjadi pada komponen pembangkitan. Rugi eksergidapat dianalisis dengan menggunakan persamaan:

$$
\text { Rugi Eksergi }=E_{\text {in }}-E_{\text {out }}-\dot{W}
$$

Setelah diketahui rugi eksergi yang terjadi pada komponen, barulah dapat dianalisis efisiensi eksergetik pada sistem dengan menggunakan persamaan:

$$
\eta=\frac{E-\text { Rugi Eksergi }}{E}
$$

\section{B. Simulasi}

Sebelumnya dilakukan terlebih dahulu simulasi untuk mengetahui performa heat exchanger sebagai proses ekstraksi panas dari geothermal brine. Pada proses simulasi heat exchanger, pertama kali yang harus dilakukan adalah menentukan daftar komponen yang adalah fluida-fluida yang ada di dalam HE tersebut yang dalam penelitian ini adalah geothermal brine dan fluida kerja (R-134a, n-pentana, dan isobutana).

Setelah menentukan daftar komponen untuk simulasi heat exchanger, kemudian dipilih property package pada menu fluid packages. Pada property package, dipilih model PengRobinson.

Setelah menentukan komponen-komponen yang terlibat dalam proses, kemudian simulasi dijalankan.Komponenkomponen disusun sesuai dengan model pembangkitan yang diinginkan. Pada model di atas, komponen-komponen yang terlibat, antara lain evaporator, ekspander (turbin), dan kondensor.

Dalam heat exchanger (evaporator) kemudian ditentukan aliran yang memasuki dan mengeluari heat exchanger. Aliran yang memasuki heat exchanger pada proses ini adalah geothermal brine yang berasal dari separator dan fluida kerja sementara aliran yang mengeluari heat exchanger pada proses ini vapor yang dihasilkan dari pemanasan fluida kerja dan geothermal brine yang panasnya sudah terekstraksi.

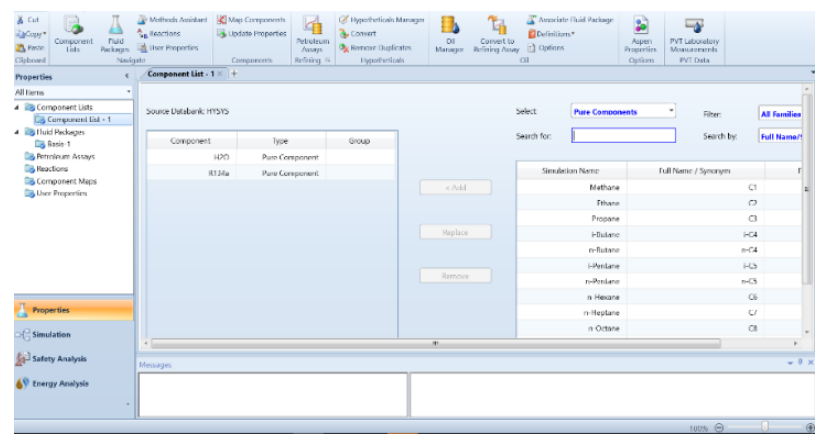

Gambar 1. Setup Fluida

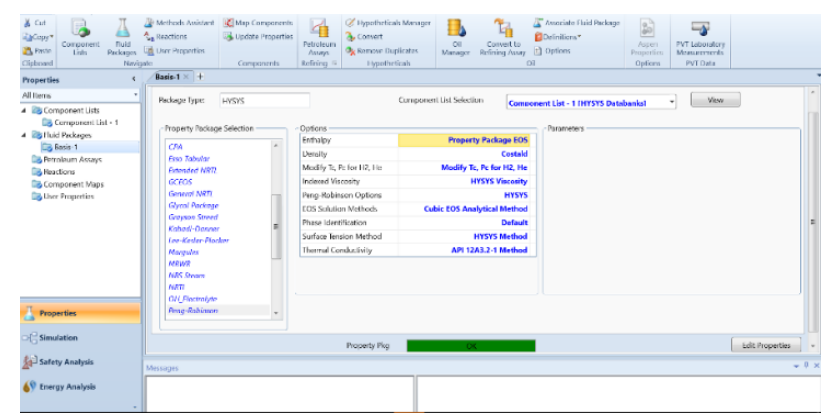

Gambar 2. Set up Fluid Package

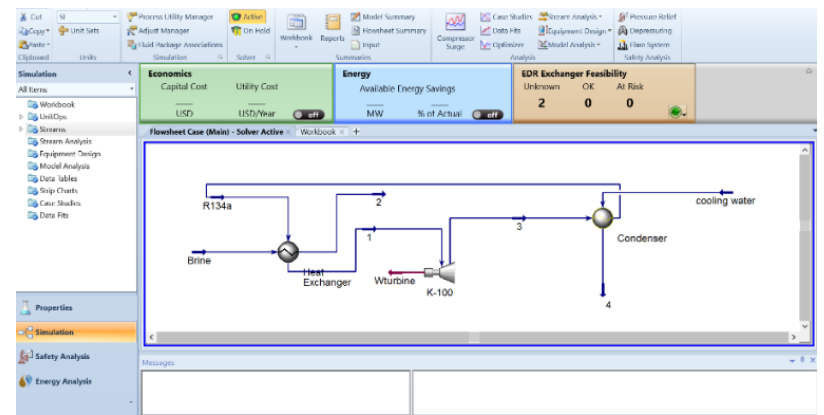

Gambar 3. Setup Model Pembangkitan 
Aliran-aliran fluida yang terlibat dalam proses simulasi ditentukan kondisi-kondisi termofisikanya. Pada aliran brine, ditentukan temperatur, pressure, fraksi massa, fraksi mol, dan mass flow ratenya.

Setelah menentukan kondisi-kondisi dari brine, kemudian ditentukan kondisi-kondisi dari fluida kerja yang diinginkan. Setelah itu, barulah dapat diketahui performa dari heat exchanger berikut dengan tabelnya. Proses simulasi selanjutnya adalah untuk mengetahui proses-proses yang terjadi pada proses pembangkitan siklus biner dengan geothermal brine. Yang dilakukan adalah dengan menyusun setiap komponen pada siklus yang meliputi heat exchanger yang sebelumnya telah diatur dan turbin. Turbin kemudian diatur aliran-aliran yang berhubungan, setelah itu ditentukan parameter-parameter pada turbin tersebut dan yang berhubungan dengan alirannya. Setelah itu barulah dapat dilihat kerja turbin pada worksheet dalam simulasi ini.

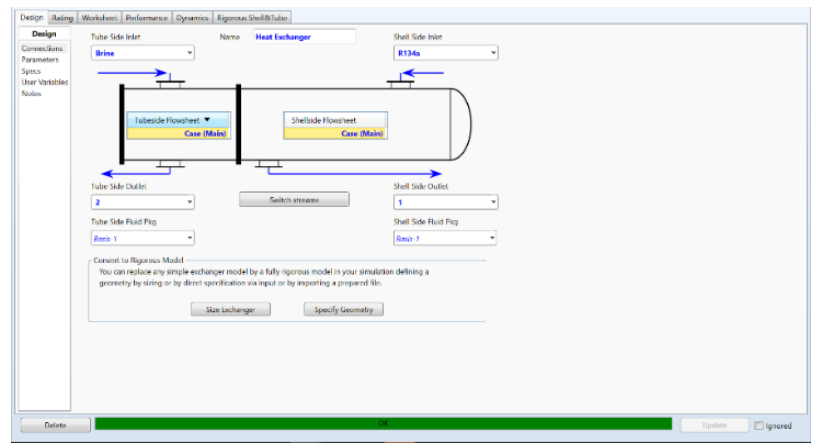

Gambar 4. Setup Evaporator

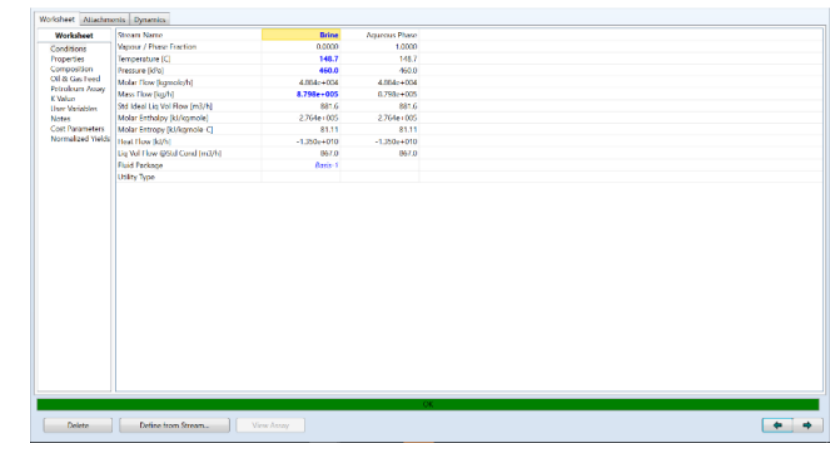

Gambar 5. Setup Properti Brine

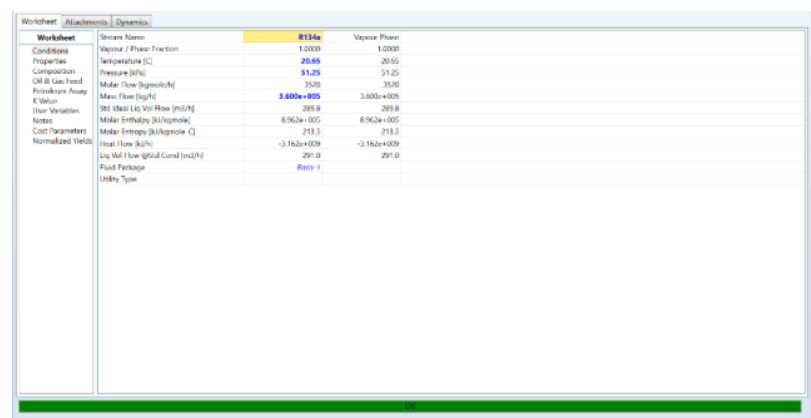

Gambar 6 Setup Properti Fluida Kerja

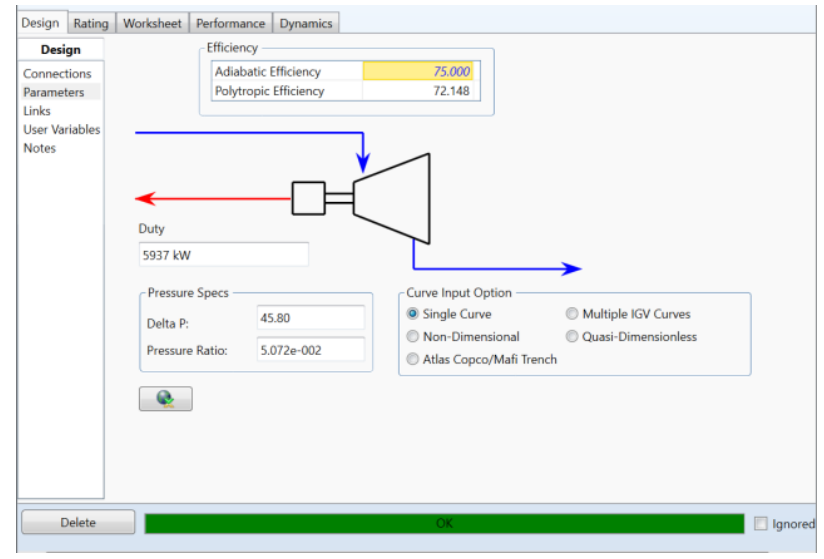

Gambar 7. Setup Turbin

III. HASIL DAN DISKUSI

\section{A. Analisis Eksergi}

Pada penelitian ini dilakukan analisis eksergi terhadap siklus biner brine dengan variasi 3 fluida sekunder atau fluida kerja yang berbeda.

Tabel 1.

Laju Eksergi R134a

\begin{tabular}{|c|r|r|r|r|r|r|}
\hline \multirow{2}{*}{$\begin{array}{c}\text { Sta } \\
\text { te }\end{array}$} & \multicolumn{1}{|c|}{$\mathrm{T}$} & \multicolumn{1}{c|}{$\mathrm{P}$} & \multicolumn{1}{c|}{$\mathrm{h}$} & \multicolumn{1}{c|}{$\mathrm{s}$} & \multicolumn{1}{c|}{$\dot{\mathrm{m}}$} & $\mathrm{E}$ \\
\hline 0 & & $\mathrm{kPa}$ & $\mathrm{kJ} / \mathrm{kg}$ & $\mathrm{kJ} / \mathrm{kgK}$ & $\mathrm{kg} / \mathrm{s}$ & $\mathrm{kW}$ \\
\hline 0 & & 17 & 71.42 & 0.253 & & \\
\hline 1 & 980 & 160 & 675.68 & 1.942 & 244.4 & 140663.271 \\
\hline 2 & 975 & 138.3 & 582.33 & 1.721 & 244.38 & 118757.854 \\
\hline 3 & 2977 & 110 & 468.15 & 1.786 & 100 & 15153 \\
\hline 4 & 900 & 33.25 & 246.44 & 1.159 & 100 & 4977.552 \\
\hline 5 & 100 & 21 & 88.19 & 0.311 & 98 & 1021.346 \\
\hline 6 & 90 & 31 & 129.99 & 0.450 & 98 & 5096.339 \\
\hline 7 & 2980 & 20.65 & 421.8 & 1.094 & 100 & 33272.95 \\
\hline
\end{tabular}

Tabel 2.

Rugi Eksergi R134a

\begin{tabular}{|l|r|}
\hline Heat Exchanger & 40025.367 \\
\hline Turbin & 3932.448 \\
\hline Kondensor & 902.559 \\
\hline
\end{tabular}

Dari data eksergi total dari brine dan total rugi eksergi pada proses, diperoleh efisiensi eksergetik sebesar $68 \%$.

Tabel 3.

Laju Eksergi n-pentana

\begin{tabular}{|c|c|r|r|r|r|r|}
\hline $\begin{array}{c}\text { Sta } \\
\text { te }\end{array}$ & $\mathrm{T}$ & $\mathrm{P}$ & \multicolumn{1}{c|}{$\mathrm{h}$} & $\mathrm{s}$ & $\mathrm{m}$ & $\mathrm{E}$ \\
\hline 0 & ${ }^{\circ} \mathrm{C}$ & $\mathrm{kPa}$ & $\mathrm{kJ} / \mathrm{kg}$ & $\mathrm{kJ} / \mathrm{kgK}$ & $\mathrm{kg} / \mathrm{s}$ & $\mathrm{kW}$ \\
\hline 0 & & 17 & 71.42 & 0.253 & & \\
\hline 1 & 980 & 160 & 675.68 & 1.841 & 244.4 & 141082.491 \\
\hline 2 & 975 & 137.8 & 621.32 & 1.636 & 244.38 & 128638.528 \\
\hline 3 & 2977 & 110 & 394.78 & 1.243 & 100 & 16496 \\
\hline
\end{tabular}




\begin{tabular}{|c|r|r|r|r|r|r|}
\hline 4 & 900 & 30.05 & 476.4 & 1.121 & 100 & 28531.448 \\
\hline 5 & 100 & 21 & 88.19 & 0.311 & 98 & 1021.346 \\
\hline 6 & 90 & 31 & 129.99 & 0.450 & 98 & 5158.272 \\
\hline 7 & 2980 & 10 & 226.41 & 1.022 & 100 & 13884.1 \\
\hline
\end{tabular}

Tabel 4.

Rugi Eksergi n-pentana

\begin{tabular}{|l|r|}
\hline Heat Exchanger & 9832.062 \\
\hline Turbin & 1007.448 \\
\hline Kondensor & 24394.523 \\
\hline
\end{tabular}

Dari data eksergi total dari brine dan total rugi eksergi pada proses, diperoleh efisiensi eks ergetik sebesar $68,7 \%$.

Tabel 5.

Laju Eksergi isobutana

\begin{tabular}{|c|c|c|c|c|c|c|}
\hline \multirow{2}{*}{$\begin{array}{l}\text { Sta } \\
\text { te }\end{array}$} & $\mathrm{T}$ & $\mathrm{P}$ & $\mathrm{h}$ & $\mathrm{s}$ & $\dot{\mathrm{m}}$ & $E$ \\
\hline & ${ }^{\circ} \mathrm{C}$ & $\mathrm{kPa}$ & $\mathrm{kJ} / \mathrm{kg}$ & $\mathrm{kJ} / \mathrm{kgK}$ & $\mathrm{kg} / \mathrm{s}$ & $\mathrm{kW}$ \\
\hline 0 & & 17 & 71.42 & 0.253 & & \\
\hline \multirow[t]{2}{*}{1} & & & & & & 140663.27 \\
\hline & 980 & 160 & 675.68 & 1.942 & 244.4 & 1 \\
\hline \multirow[t]{2}{*}{2} & & & & & & 118757.85 \\
\hline & 975 & 138.3 & 582.33 & 1.721 & 244.38 & 4 \\
\hline 3 & 2977 & 110 & 401.29 & 1.513 & 100 & 12823.800 \\
\hline 4 & 900 & 31.8 & 241.2 & 1.159 & 100 & 4453.552 \\
\hline 5 & 100 & 21 & 88.19 & 0.311 & 98 & 1021.346 \\
\hline 6 & 90 & $\overline{31}$ & 129.99 & 0.450 & 98 & 5124.402 \\
\hline 7 & 2980 & 20.65 & 421.8 & 1.094 & 100 & 33272.950 \\
\hline
\end{tabular}

Tabel 6.

Rugi Eksergi isobutana

\begin{tabular}{|l|r|}
\hline Heat Exchanger & 42354.567 \\
\hline Turbin & 2228.248 \\
\hline Kondensor & 350.496 \\
\hline
\end{tabular}

Dari data eksergi total dari brine dan total rugi eksergi pada proses, diperoleh efisiensi eksergetik sebesar $68,1 \%$.

\section{B. Simulasi}

Tabel 7.

Simulasi R134a

\begin{tabular}{|c|r|r|r|}
\hline Daya Turbin & \multicolumn{3}{|c|}{$6064 \mathrm{~kW}$} \\
\hline \multirow{2}{*}{ State } & \multicolumn{1}{|c|}{$\mathbf{P}$} & \multicolumn{1}{c|}{$\mathbf{T}$} & \multicolumn{1}{c|}{$\mathbf{h}$} \\
\cline { 2 - 4 } & $\mathbf{k P a}$ & \multicolumn{1}{c|}{$\mathbf{C}$} & $\mathbf{~ k J / k g}$ \\
\hline Brine & 980 & 150 & 632.49 \\
\hline R134a & 2980 & 20.65 & 228.63 \\
\hline HE-Turbin & 2977 & 100 & 453.59 \\
\hline Turbin-Cond & 900 & 33.25 & 246.44 \\
\hline Cooling Water & 100 & 21 & 88.19 \\
\hline Reservoir & 975 & 129.3 & 582.29 \\
\hline Cooling Tower & 90 & 31 & 129.99 \\
\hline
\end{tabular}

Tabel 8.

Simulasi n-pentana

\begin{tabular}{|c|c|c|c|}
\hline $\begin{array}{c}\text { Daya } \\
\text { Turbin }\end{array}$ & \multicolumn{3}{|c|}{$12940 \mathrm{~kW}$} \\
\hline \multirow{2}{*}{ State } & $\mathbf{P}$ & $\mathbf{T}$ & $\mathbf{h}$ \\
\cline { 2 - 4 } & $\mathbf{k P a}$ & $\mathbf{0} \mathbf{C}$ & $\mathbf{k J} / \mathbf{k g}$ \\
\hline Brine & 980 & 150 & 632.49 \\
\hline n-pentana & 2980 & 10 & 226.41 \\
\hline HE-Turbin & 2977 & 100 & 358.89 \\
\hline Turbin-Cond & 900 & 30.05 & 232.4 \\
\hline $\begin{array}{c}\text { Cooling } \\
\text { Water }\end{array}$ & 100 & 21 & 88.19 \\
\hline Reservoir & 975 & 130.2 & 570.35 \\
\hline $\begin{array}{c}\text { Cooling } \\
\text { Tower }\end{array}$ & 90 & 31 & 129.99 \\
\hline
\end{tabular}

Tabel 9.

Simulasi isobutana

\begin{tabular}{|c|c|c|c|}
\hline Daya Turbin & \multicolumn{3}{|c|}{$5986 \mathrm{~kW}$} \\
\hline \multirow{2}{*}{ State } & $\mathrm{P}$ & $\mathrm{T}$ & $\mathrm{h}$ \\
\cline { 2 - 4 } & $\mathrm{kPa}$ & ${ }^{0} \mathrm{C}$ & $\mathrm{kJ} / \mathrm{kg}$ \\
\hline Brine & 980 & 150 & 632.49 \\
\hline isobutana & 2980 & 15 & 238.47 \\
\hline HE-Turbin & 2977 & 100 & 392.58 \\
\hline Turbin-Cond & 900 & 31.8 & 241.2 \\
\hline Cooling Water & 100 & 21 & 88.19 \\
\hline Reservoir & 975 & 131.4 & 552.83 \\
\hline $\begin{array}{c}\text { Cooling } \\
\text { Tower }\end{array}$ & 90 & 31 & 129.99 \\
\hline
\end{tabular}

Melalui simulasi, dapat disimpulkan bahwa fluida sekunder atau fluida kerja pada siklus biner yang paling baik jika ditinjau dari daya yang dihasilkan adalah n-pentana. Meski demikian, dari data di atas dan dari hasil analisis eksergi dapat dilihat bahwa termalyang terbuang untuk proses reinjeksi ke reservoir masih cenderung besar. Oleh sebab itu diperlukan rekayasa terhadap model pembangkitan salah satunya adalah dengan penambahan komponen preheater pada siklus.

Pada gambar di atas, dapat dilihat grafik perbandingan antara ketiga fluida sekunder atau fluida kerja yang digunakan dalam penelitian ditinjau dari daya pada turbin yang dihasilkan pada proses pembangkitan. Dapat dilihat bahwa n-pentane merupakan fluida sekunder atau fluida kerja terbaik jika ditinjau dari daya turbin yang dihasilkan.

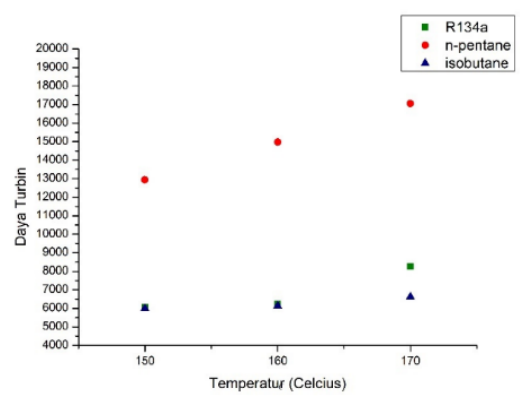

Gambar 8. Grafik Perbandingan Fluida Kerja 
Tabel 10.

Simulasi dengan preheater (R134a)

\begin{tabular}{|c|r|r|r|}
\hline Daya Turbin & \multicolumn{3}{|c|}{$6862 \mathrm{~kW}$} \\
\hline \multirow{2}{*}{ State } & \multicolumn{1}{|c|}{$\mathbf{P}$} & \multicolumn{1}{c|}{$\mathbf{T}$} & \multicolumn{1}{c|}{$\mathbf{h}$} \\
\cline { 2 - 4 } & $\mathbf{k P a}$ & \multicolumn{1}{c}{$\mathbf{C}$} & $\mathbf{~ k J / k g}$ \\
\hline Brine & 980 & 150 & 632.49 \\
\hline R134a & 2980 & 20.65 & 228.63 \\
\hline HE-Turbin & 2977 & 100 & 453.59 \\
\hline Turbin-Cond & 900 & 35.4 & 249.59 \\
\hline Cooling Water & 100 & 31 & 130 \\
\hline Reservoir & 975 & 113.4 & 497.5 \\
\hline Cooling Tower & 90 & 21 & 88.18 \\
\hline \multicolumn{4}{|c}{}
\end{tabular}

Dengan penambahan komponen preheater pada siklus, dapat dilihat penambahan dari daya yang dihasilkan oleh siklus. Dapat dilihat juga termal yang akan direinjeksi sudah tidak memiliki potensi untuk pembangkitan lagi.

\section{KESIMPULAN}

Berdasarkan hasil dari simulasi dan analisis data yang telah dilakukan, maka kesimpulan dari penelitian ini antara lain:

a. Pemanfaatan dari Geothermal Brine dapat dilakukan dengan menggunakan siklus biner dan akan lebih optimal dengan siklus menggunakan preheater. Dengan menggunakan siklus preheater daya yang dihasilkan meningkat menjadi $6862 \mathrm{~kW}$ dari $6064 \mathrm{~kW}$ pada siklus tanpa preheater.

b. Fluida kerja atau fluida sekunder yang paling baik jika ditinjau dari efisiensi eksergetik dan daya yang dihasilkan adalah fluida n-pentana dengan mampu menghasilkan daya hingga $17060 \mathrm{~kW}$ dengan efisiensi eksergetik hingga $68,7 \%$.

c. Dari analisis eksergi yang telah dilakukan, dapat dilihat bahwa rugi eksergi yang paling besar terjadi pada reinjeksi ke reserovoir, hal ini dapat diminimalisir dengan menggunakan preheater sehingga panas yang dibuang terlebih dahulu dimanfaatkan untuk proses preheating.

\section{UCAPAN TERIMA KASIH}

Penulis mengucapkan terima kasih kepada civitas academica Departemen Teknik Fisika ITS yang telah mendukung dilakukannya penelitian ini. Khususnya kepada Laboratorium Rekayasa Energi dan Pengondisian Lingkungan serta Dr. Ridho Hantoro, ST, MT. yang senantiasa membimbing sehingga penelitian ini dapat berjalan dengan baik dan lancar.

\section{DAFTAR PUSTAKA}

[1] N. Saptadji, "Energi Panas Bumi (Geothermal Energy)," 2009. [2] F. P. and G. Abdurrahman, "Geothermal Brine from Waste to Alternative Thermal Energy Source," 2016.

[3] T. M. and C. Antal, "Power Generation from Low-Enthalpy Geothermal Resources," 2001.

[4] R. DiPippo, "Geothermal Power P lants: Principles, Applications, Case Studies, and Environmental Impact," 2008. 